\title{
Qualidade de sementes e desenvolvimento inicial de plântulas de pimenta malagueta e sua relação com a posição de coleta de frutos ${ }^{1}$
}

\author{
Liana Hilda Golin Mengarda ${ }^{2}$, José Carlos Lopes ${ }^{2 *}$
}

\begin{abstract}
RESUMO - O objetivo neste estudo foi avaliar a relação entre a posição de coleta dos frutos de pimenta malagueta na planta, a qualidade das sementes e o desenvolvimento inicial das plântulas. As sementes foram obtidas de frutos coletados em diferentes posições na copa (C) e nos ramos (R): 1- apical, 2- mediana e 3- basal, e avaliados o teor de água, peso de mil sementes (PMS), número de sementes por quilo, tamanho de sementes (comprimento, largura e espessura), germinação e vigor pelo índice de velocidade de germinação (IVG), tempo médio de germinação (TMG), comprimento da raiz, parte aérea, massa fresca e massa seca das plântulas após 28 dias da semeadura. As sementes de frutos coletados na porção basal e mediana da copa, e basal dos ramos (C2R3 e C3R3) apresentaram maior PMS, associado ao maior comprimento e largura. Estes tratamentos apresentaram maior valor para a porcentagem de germinação, maior índice de velocidade de germinação e menor tempo médio de germinação. Além do maior vigor, as sementes provenientes de frutos coletados na região basal (C3R3) propiciaram o melhor desenvolvimento inicial de plântulas com relação ao comprimento da raiz, massa fresca e seca de plântulas.
\end{abstract}

Termos para indexação: Capsicum frutescens, germinação, qualidade fisiológica.

\section{Seed quality and initial seedling growth of malagueta pepper and their relationship to the position of fruit collection}

\begin{abstract}
The objective of this study was to evaluate the relationship between the collection position of fruits from the malagueta pepper plant and seed quality and initial seedling development. The seeds were obtained from fruits collected at different positions in the canopy (C) and branches (R): 1 - apical, 2 - median, and 3 - basal. The following evaluations were made: water content, seed weight (PMS), number of seeds per kilogram, seed size (1ength, width and thickness), germination and vigor, according to the germination speed index (IVG), the average time of germination (TMG), root and seedling length, and the fresh and dry weights of seedlings 28 days after sowing. Seeds from fruits collected from the basal and median positions of the canopy, and base of branches (C2R3 and C3R3) had a higher PMS, associated with a greater seed length and width. These treatments also showed a higher germination percentage, germination speed index and lower mean germination time. Besides the higher vigor, seeds from fruits collected in the basal region (C3R3) show greater plant development for root length and fresh and dry weight of the seedlings.
\end{abstract}

Index terms: Capsicum frutescens, germination, physiological quality.

\section{Introdução}

A pimenta é uma importante especiaria, símbolo da culinária mundial, que vem ganhando destaque, como alimento funcional, devido ao seu alto valor nutricional dos seus frutos, ricos em vitaminas $\mathrm{A}, \mathrm{C} \mathrm{e} \mathrm{E}$, carotenos, minerais fundamentais

${ }^{1}$ Submetido em 25/08/2011. Aceito para publicação em 11/05/2012.

${ }^{2}$ Departamento de Produção Vegetal, UFES, 29075-910-Vitória, ES, Brasil

*Autor para correspondência <jcufes@bol.com.br> 
e substâncias antioxidantes (Reifschneider, 2000; Conforti et al., 2007). Estas características conferem valor comercial e maior importância à cultura da pimenta, quem vem se tornando a fonte primária de renda para pequenos e médios agricultores, principalmente nos estados de MG, BA e GO (Reifschneider, 2000).

As pimenteiras pertencem à família Solanaceae, gênero Capsicum. São caracterizadas agronomicamente como cultura olerícola, e as principais espécies cultivadas no Brasil são Capsicum frutescens (pimenta malagueta), C. baccatum (dedo-de-moça), C. chinese (de cheiro), $C$. praetermissum, C. annuum (jalapeño) (Filgueira, 2003).

A pimenta malagueta (C. frutescens) é uma das variedades mais conhecidas e amplamente utilizadas no país. Suas plantas são arbustivas, bastante ramificadas. Os frutos são cônicos, eretos, de parede muito delgada, com polpa mole. Antes de estarem maduros seus frutos apresentam coloração verde, e já podem ser consumidos. Quando maduros, tornam-se vermelhos, atingindo entre 1,5 e $3 \mathrm{~cm}$ de comprimento, e 0,4 a $0,5 \mathrm{~cm}$ de largura. Suas sementes apresentam coloração palha, e são mais espessas na região do hilo (Reifschneider, 2000).

Em todos os segmentos da produção vegetal, a produção de frutos com melhores características agronômicas e industriais requer, primordialmente, a utilização de sementes de alta qualidade na produção das mudas. É consenso entre os pesquisadores, tecnologistas e produtores de sementes, a importância do vigor e a necessidade de avaliá-lo (Marcos-Filho, 1999). Por este motivo, pesquisas acerca da qualidade de sementes de pimenta vêm sendo realizadas, investigando o processo de maturação (Oliveira et al., 1999; Vidigal et al., 2009), o potencial fisiológico por meio de teste de envelhecimento acelerado (Torres, 2005; Bhering et al., 2006) e condutividade elétrica (Vidigal et al., 2008; 2009), além de estudos de interações bióticas e abióticas na germinação (Rueda-Poente et al., 2010).

De acordo com estudos sobre a maturação dos frutos, Vidigal et al. (2009) verificaram que colheitas precoces acarretam prejuízos à qualidade fisiológica das sementes, prejudicando a germinação, a emergência e o desenvolvimento das mudas de Capsicum annuum. Em espécies que apresentam frutificação heterogênea, como é comum no gênero Capsicum, são encontrados frutos em diversas fases de maturação distribuídos de maneira desigual nos ramos (Pereira e Mantovani, 2001) e assim, a posição na qual estão dispostos os frutos na planta, pode estar relacionada com diferentes estádios de desenvolvimento e maturidade dos frutos e sementes.
Além disso, sob os diferentes estratos da copa, diferentes quantidade e qualidade de luz incidem sobre as folhas, o que condiciona a produção e translocação de fotoassimilados de forma diferenciada entre as porções da copa e dos ramos. Este padrão de alocação parcial de nutrientes é observado em espécies que apresentam produção estendida (Pereira e Mantovani, 2001), como a pimenteira que pode estender a produção por mais de um ano (Reindeschefer, 2000). Nestes casos, os fotoassimilados são distribuídos em pulsos de maneira a suprir a planta nos diferentes estádios, à medida que a mesma solicita recursos para finalizar os processos de desenvolvimento vegetativos ou reprodutivos, entre eles, o desenvolvimento dos frutos e sementes (Pereira e Mantovani, 2001). Desta forma, a posição que os frutos ocupam na copa e nos ramos pode estar relacionada ao desenvolvimento diferencial de frutos e à qualidade das sementes formadas. A investigação da influência da posição de coleta na qualidade física e fisiológica de sementes pode, portanto, trazer informações tecnológicas relevantes para a obtenção de sementes que apresentem melhor qualidade física e fisiológica, em estádio ideal de maturação, e, assim, na obtenção de plantas mais vigorosas.

Com base nisso, objetivou-se com o presente trabalho avaliar a qualidade física e fisiológica de sementes coletadas em diferentes porções da copa e dos ramos de pimenteira ( $C$. frutescens), inferindo sobre os procedimentos adequados de coleta de frutos para a obtenção de sementes de maior vigor.

\section{Material e Métodos}

O trabalho foi desenvolvido no Laboratório de Análise de Sementes (LAS), do Centro de Ciências Agrárias da Universidade Federal do Espírito Santo (CCA-UFES). Foram utilizadas sementes de pimenta malagueta coletadas de matrizes propagadas pelo LAS. As sementes foram obtidas pela coleta de frutos em diferentes combinações da posição na copa (C), no ramo (R) e nas porções: apical (1), mediana (2) e basal (3). Assim, foram estabelecidos nove tratamentos: C1R1 (porções apicais da copa e do ramo); C1R2 (porção apical da copa e mediana do ramo); C1R3 (porção apical da copa e na base do ramo); C2R1 (porção mediana da copa e no ápice do ramo); C2R2 (porções medianas da copa e do ramo); C2R3 (porção mediana da copa e na base do ramo); C3R1 (porção basal da copa e no ápice do ramo); C3R2 (porção basal da copa e mediana do ramo) e C3R3 (porções basais da copa e do ramo).

Foram selecionados frutos maduros, apresentando coloração vermelha, isentos de qualquer indício de 
deterioração. Os frutos apresentavam tamanho médio de 2,04 $\mathrm{cm}$ de comprimento $(1,50-2,42 \mathrm{~cm}) \times 0,52 \mathrm{~cm}$ de largura $(0,45-0,65 \mathrm{~cm})$. Os frutos recém coletados foram abertos e, com auxílio de pinça e espátula, retiradas as sementes. Estas foram lavadas em água corrente, sofreram assepsia em álcool $70 \%$ por 5 minutos + hipoclorito $2 \%$ por 2 minutos, enxaguadas em água destilada por três vezes, e deixadas secar sob papel toalha. Em seguida, foram acondicionadas em potes herméticos, em temperatura ambiente.

Teor de água: o teor de água das sementes foi obtido por meio do método de estufa à baixa temperatura (105 \pm $3{ }^{\circ} \mathrm{C}$ por 24 horas), conforme Brasil (2009), usando quatro subamostras de 25 sementes para cada tratamento. Os resultados foram expressos em porcentual.

Peso de mil sementes (PMS): para a determinação do PMS foram usadas oito repetições de 25 sementes, e o valor obtido calculado de acordo com Brasil (2009).

Tamanho das sementes: foi obtido com o auxílio de paquímetro analógico, verificando-se altura, largura (lado mais largo) e espessura (lado mais estreito) das sementes, utilizando quatro repetições de 25 sementes para cada tratamento.

Germinação: a semeadura foi feita em placas de Petri forradas com papel "germitest" umedecido com água destilada (7 mL). Foram utilizadas quatro repetições de 25 sementes para cada tratamento. As placas foram colocadas em câmara de germinação tipo BOD regulada à temperatura de $20-30{ }^{\circ} \mathrm{C}$. Baseado em contagem diária de germinação, foram calculados a porcentagem de germinação $(\mathrm{G})$, tempo médio de germinação (TMG), e o índice de velocidade de germinação (IVG) conforme a equação proposta por Maguire (1962):

$\mathrm{IVG}=\mathrm{G} 1 / \mathrm{N} 1+\mathrm{G} 2 / \mathrm{N} 2+\ldots+\mathrm{Gn} / \mathrm{Nn}$, onde:

$\mathrm{G} 1, \mathrm{G} 2, \ldots \mathrm{Gn}=$ número de plântulas normais computadas na primeira, na segunda e na última contagem.

$\mathrm{N} 1, \mathrm{~N} 2, \ldots \mathrm{Nn}=$ número de dias de semeadura à primeira, segunda e última contagem.

Comprimento e massa das plântulas: aos 28 dias após a instalação do experimento foram avaliados o comprimento da raiz e da parte aérea das plântulas normais, e calculadas a massa fresca e massa seca (estufa de circulação forçada $80{ }^{\circ} \mathrm{C}$ por $72 \mathrm{~h}$ ). Foram consideradas normais as plantas completas, constituídas das partes: raiz primária (raízes secundárias), hipocótilo e cotilédones.

Delineamento estatístico: o experimento foi estabelecido em delineamento inteiramente casualizado (DIC), com nove tratamentos e quatro repetições de 25 sementes por tratamento. Os resultados obtidos foram submetidos à análise de variância e realizada a comparação das médias pelo teste de Scott-Knott, no nível de 1\% de probabilidade.

\section{Resultados e Discussão}

A posição de coleta apresentou influência na qualidade física e fisiológica das sementes de pimenta malagueta. Com relação à análise física (Tabela 1), não foi verificada diferença significativa para o teor de água entre as sementes oriundas de frutos de diferentes posições da planta. Com relação ao peso de mil sementes (PMS), evidenciou-se valor significativamente superior em C3R2, seguido de C3R3. Foram observados maiores valores médios de comprimento e largura de sementes obtidas de frutos coletados nas porções mediana (2) e basal (3) da copa e dos ramos (C2R3, C3R2 e C3R3). Verifica-se, portanto, que as sementes de frutos coletados na porção basal da copa e dos ramos, apresentaram maior tamanho (comprimento e largura), associado ao maior peso.

Tabela 1. Características físicas de sementes de Capsicum frutescens provenientes de frutos coletados em diferentes posições na copa da planta: teor de água (U), peso de mil sementes (PMS), número de sementes por $\mathrm{Kg}_{\mathrm{g}}\left(\mathrm{S} \mathrm{k}^{-1}\right)$, comprimento médio $(\mathrm{C})$, largura média $(\mathrm{L})$, espessura média $(\mathrm{E})$.

\begin{tabular}{ccccccc}
\hline Posição & $\mathrm{U}(\%)$ & PMS $(\mathrm{g})$ & $\mathrm{S} \mathrm{kg}^{-1}\left(10^{5}\right)$ & $\mathrm{C}(\mathrm{mm})$ & $\mathrm{L}(\mathrm{mm})$ & $\mathrm{E}(\mathrm{mm})$ \\
\hline C1R1 & $8,25 \mathrm{a}$ & $2,14 \mathrm{~d}$ & $4,71 \mathrm{~b}$ & $3,09 \mathrm{~b}$ & $2,45 \mathrm{c}$ & $0,68 \mathrm{a}$ \\
C1R2 & $9,13 \mathrm{a}$ & $2,21 \mathrm{~d}$ & $4,58 \mathrm{~b}$ & $3,13 \mathrm{~b}$ & $2,49 \mathrm{c}$ & $0,64 \mathrm{a}$ \\
C1R3 & $8,71 \mathrm{a}$ & $2,27 \mathrm{~d}$ & $4,42 \mathrm{~b}$ & $2,87 \mathrm{c}$ & $2,41 \mathrm{c}$ & $0,63 \mathrm{a}$ \\
C2R1 & $7,24 \mathrm{a}$ & $2,24 \mathrm{~d}$ & $4,48 \mathrm{~b}$ & $3,05 \mathrm{~b}$ & $2,61 \mathrm{~b}$ & $0,61 \mathrm{a}$ \\
C2R2 & $7,72 \mathrm{a}$ & $1,97 \mathrm{e}$ & $5,12 \mathrm{a}$ & $3,16 \mathrm{~b}$ & $2,58 \mathrm{c}$ & $0,56 \mathrm{a}$ \\
C2R3 & $7,78 \mathrm{a}$ & $2,52 \mathrm{c}$ & $3,98 \mathrm{c}$ & $3,13 \mathrm{~b}$ & $2,70 \mathrm{a}$ & $0,64 \mathrm{a}$ \\
C3R1 & $7,82 \mathrm{a}$ & $2,35 \mathrm{c}$ & $4,25 \mathrm{~b}$ & $3,09 \mathrm{~b}$ & $2,51 \mathrm{c}$ & $0,64 \mathrm{a}$ \\
C3R2 & $7,57 \mathrm{a}$ & $3,12 \mathrm{a}$ & $3,21 \mathrm{~d}$ & $3,32 \mathrm{a}$ & $2,75 \mathrm{a}$ & $0,65 \mathrm{a}$ \\
C3R3 & $7,26 \mathrm{a}$ & $2,92 \mathrm{~b}$ & $3,43 \mathrm{~d}$ & $3,32 \mathrm{a}$ & $2,75 \mathrm{a}$ & $0,65 \mathrm{a}$ \\
\hline
\end{tabular}

Médias seguidas de letras distintas diferem entre si pelo teste de Scott-Knott a 1\% de probabilidade $(n=4)$. 
O PMS é uma informação que dá ideia do tamanho das sementes, assim como de seu estado de maturidade e de sanidade (Brasil, 2009). De acordo com PiñaRodrigues e Aguiar (1993), o maior peso de matéria seca das sementes tem sido apontado como o indicador físico mais seguro quanto ao estádio de maturidade fisiológica. Segundo os mesmos autores, o teor de água poderia ser também um dos indicativos do estádio de maturação da semente. No entanto, não foi observada variação significativa com relação ao teor de água para as sementes provenientes de frutos das diferentes posições da planta de $C$. frutescens. Entretanto, com base nestas informações e, de acordo com os resultados obtidos no presente estudo, a disposição dos frutos na planta pode ser um indicativo da maturidade se baseada na qualidade física das sementes: os frutos posicionados na região basal e mediana da copa e dos ramos (C3R2 e C3R3) apresentaram sementes de maior tamanho e maior PMS (maior massa seca de sementes).

As modificações visuais no aspecto externo das sementes, ou seja, suas características físicas podem ser usadas como indicadores da maturidade fisiológica, a partir dos quais podemos obter um índice de qualidade de sementes direto, de observação prática e fácil utilização em condições de campo, se comparado aos índices bioquímicos e fisiológicos (Piña-Rodrigues e Aguiar, 1993). Por outro lado, o estudo do processo de maturação envolve observações complexas sobre as modificações de natureza morfológica (como tamanho, teor de água, conteúdo de massa seca) com as modificações de natureza fisiológica (germinação e vigor), além das características bioquímicas (PiñaRodrigues e Aguiar, 1993; Vidigal et al., 2009). A maturação de sementes pode ser acompanhada, principalmente, por meio de avaliações do teor de água e do peso da massa seca, aliadas à avaliação da porcentagem e velocidade de germinação. Em geral, durante a fase de maturação fisiológica, sementes ortodoxas se desligam da planta mãe, cessando a translocação dos fotoassimilados, levando a planta a acionar mecanismos para promover a desidratação das sementes, e este momento seria aquele onde as sementes apresentam máximo poder germinativo, máximo vigor e maior peso de massa seca (Piña-Rodrigues e Aguiar, 1993). Fica evidente, assim, a necessidade de investigar conjuntamente as características físicas e fisiológicas como possíveis indicadores de qualidade e maturidade da semente.

No caso de $C$. frutescens foi verificado que as sementes provenientes de frutos coletados da posição basal, além de apresentaram maior massa seca e maior tamanho, fatores estes atribuídos a maior qualidade física, também apresentaram qualidade fisiológica superior.

Verificaram-se maiores valores de germinação (98 e 96\%) para as sementes provenientes de frutos coletadas na região basal da copa e mediana e basal dos ramos (C3R2 e C3R3), não diferindo de C1R3 (Tabela 2). Maior índice de velocidade de germinação $(\mathrm{IVG}=3,20)$ e menor tempo médio de germinação (TMG $=7,69$ dias) foram observados em sementes de frutos coletados na porção basal da copa e dos ramos (C3R3). Verifica-se ainda, uma relação direta entre o aumento do peso de matéria seca de sementes (PMS) com o aumento do IVG, conforme pode ser observado na Figura 1, e, consequentemente, redução do $\mathrm{TMG}$ (Tabela 2). No caso de C. frutescens, esta relação pode ser um parâmetro prático de avaliação, baseado nas características físicas, pois sementes de maior peso apresentam melhor qualidade fisiológica.

As combinações C3R2 e C3R3 também foram as posições de coleta de frutos as quais, após a germinação das sementes, observou-se melhor desenvolvimento das plântulas com relação à massa fresca $(16,23 \mathrm{mg}$ e 17,12 mg) e massa seca totais $(0,84 \mathrm{mg}$ e $0,83 \mathrm{mg})$, respectivamente, conforme constatado na Tabela 3.

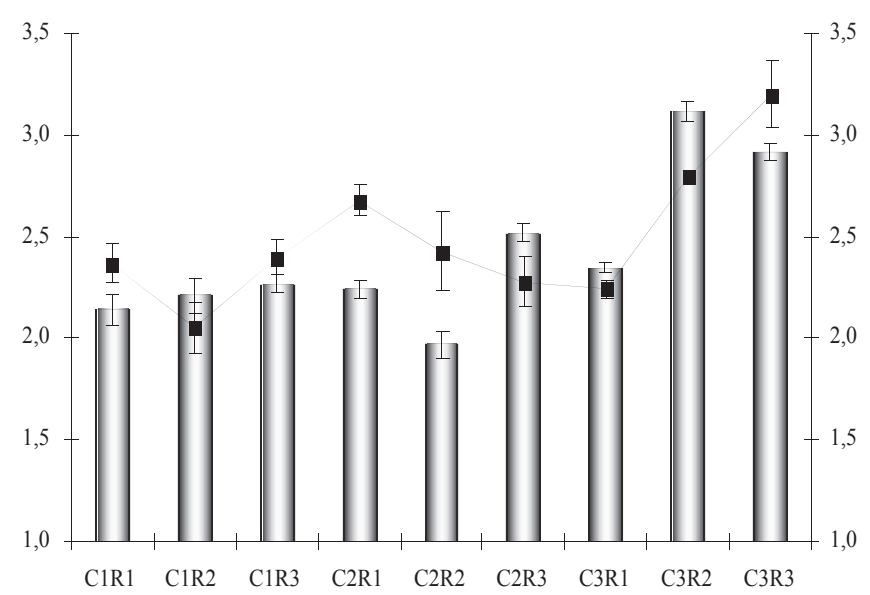

Figura 1. Peso de mil sementes, em gramas (colunas) e índice de velocidade de germinação (linha) de sementes de Capsicum frutescens provenientes de frutos coletados em diferentes posições da copa (C) e dos ramos (R), nas porções apical (1), mediana (2) e basal (3). As barras representam o erro padrão da média $(n=4)$. 
Tabela 2. Germinação (G), índice de velocidade de germinação (IVG) e tempo médio de germinação (TMG) de sementes de Capsicum frutescens provenientes de frutos coletados em diferentes posições da copa e dos ramos.

\begin{tabular}{cccc}
\hline Posição & G (\%) & IVG & TMG (dias) \\
\hline C1R1 & $88 \mathrm{~b}$ & $2,37 \mathrm{c}$ & $9,66 \mathrm{~b}$ \\
C1R2 & $87 \mathrm{~b}$ & $2,05 \mathrm{c}$ & $11,15 \mathrm{a}$ \\
C1R3 & $96 \mathrm{a}$ & $2,40 \mathrm{c}$ & $10,47 \mathrm{a}$ \\
C2R1 & $93 \mathrm{~b}$ & $2,68 \mathrm{~b}$ & $8,92 \mathrm{c}$ \\
C2R2 & $79 \mathrm{~b}$ & $2,43 \mathrm{c}$ & $8,59 \mathrm{c}$ \\
C2R3 & $85 \mathrm{~b}$ & $2,28 \mathrm{c}$ & $9,66 \mathrm{~b}$ \\
C3R1 & $93 \mathrm{~b}$ & $2,24 \mathrm{c}$ & $10,72 \mathrm{a}$ \\
C3R2 & $98 \mathrm{a}$ & $2,80 \mathrm{~b}$ & $9,00 \mathrm{c}$ \\
C3R3 & $96 \mathrm{a}$ & $3,20 \mathrm{a}$ & $7,69 \mathrm{~d}$ \\
\hline CV $(\%)$ & 9,84 & 3,86 & 5,52 \\
\hline
\end{tabular}

Médias seguidas de letras distintas diferem entre si pelo teste de ScottKnott a $1 \%$ de probabilidade $(n=4)$.

Tabela 3. Comprimento de raiz (Raiz), da parte aérea (PA), massa fresca (MF) e massa seca (MS) das plântulas de Capsicum frutescens, após 28 dias da semeadura de sementes provenientes de frutos coletados em diferentes posições na planta.

\begin{tabular}{ccccc}
\hline Posição & $\begin{array}{c}\text { Raiz } \\
(\mathrm{cm})\end{array}$ & PA (cm) & MF (mg) & $\begin{array}{c}\text { MS } \\
(\mathrm{mg})\end{array}$ \\
\hline C1R1 & $0,37 \mathrm{~b}$ & $3,28 \mathrm{a}$ & $12,96 \mathrm{~b}$ & $0,62 \mathrm{~b}$ \\
C1R2 & $0,39 \mathrm{~b}$ & $3,40 \mathrm{a}$ & $13,36 \mathrm{~b}$ & $0,66 \mathrm{~b}$ \\
C1R3 & $0,41 \mathrm{~b}$ & $3,53 \mathrm{a}$ & $12,91 \mathrm{~b}$ & $0,61 \mathrm{~b}$ \\
C2R1 & $0,40 \mathrm{~b}$ & $3,51 \mathrm{a}$ & $13,71 \mathrm{~b}$ & $0,69 \mathrm{~b}$ \\
C2R2 & $0,40 \mathrm{~b}$ & $3,54 \mathrm{a}$ & $13,55 \mathrm{~b}$ & $0,59 \mathrm{~b}$ \\
C2R3 & $0,37 \mathrm{~b}$ & $3,56 \mathrm{a}$ & $14,50 \mathrm{~b}$ & $0,70 \mathrm{~b}$ \\
C3R1 & $0,35 \mathrm{~b}$ & $3,23 \mathrm{a}$ & $12,24 \mathrm{~b}$ & $0,64 \mathrm{~b}$ \\
C3R2 & $0,46 \mathrm{~b}$ & $3,55 \mathrm{a}$ & $16,23 \mathrm{a}$ & $0,84 \mathrm{a}$ \\
C3R3 & $0,58 \mathrm{a}$ & $3,79 \mathrm{a}$ & $17,12 \mathrm{a}$ & $0,83 \mathrm{a}$ \\
\hline CV (\%) & 11,19 & 10,92 & 8,18 & 8,70 \\
\hline
\end{tabular}

Médias seguidas de letras distintas diferem entre si pelo teste de ScottKnott a $1 \%$ de probabilidade $(n=4)$.

Durante o ciclo da planta, diversos eventos ocorrem ao mesmo tempo: crescimento vegetativo, surgimento de gemas reprodutivas, florescimento, crescimento e maturação de frutos e sementes. Por conta disso, o fluxo de carboidratos para os frutos pode ocorrer de forma desigual quando existe mais de um fruto por ramo. Em culturas como o algodoeiro, isso explica porque os frutos localizados na posição basal dos ramos são mais desenvolvidos que os demais, entretanto, quanto mais alta a posição do capulho na planta e mais afastado da haste principal ele estiver (posição apical), menor o peso médio e menor o rendimento (Pereira e Mantovani, 2001). Dias et al. (2006) observaram que a maturidade dos frutos e a maturação fisiológica das sementes de tomate estão relacionadas com a posição que estes ocupam na planta. Em geral, nas espécies do gênero Capsicum são encontrados frutos distribuídos de maneira desigual nos ramos.

Dependendo da arquitetura da copa, e da incidência de luz entre os estratos, a produção e translocação de fotoassimilados podem ocorrer de forma diferenciada, favorecendo determinadas porções da copa ou dos ramos, influenciando o desenvolvimento e maturação dos frutos e sementes. Assim, a porção que os frutos ocupam pode ter relação com diferentes fases de desenvolvimento e maturação dos frutos, influenciando assim, a maturidade fisiológica e qualidade das sementes (Pereira e Mantovani, 2001; Dias et al., 2006).

Ao atingirem a maturidade fisiológica, as sementes possuem condições ideais para apresentarem o máximo poder germinativo e máximo vigor (Piña-Rodrigues e Aguiar, 1993). Esta relação entre a maturidade fisiológica e resultados superiores de germinação e vigor são descritas em diversas espécies, Cedrela fissilis (Corvello et al., 1999); Miconia cinnamomifolia (Pereira e Mantovani, 2001); Tibouchina granulosa (Lopes et al., 2005); Capsicum annuum (Vidigal et al., 2008; 2009); Eugenia uniflora (Ávila et al., 2009); e Erythrina crista-galli (Lazarotto et al., 2011).

São muito comuns os estudos que relacionam a maturação fisiológica de sementes com o seu tempo de origem (dias após a antese). Em geral, estes estudos têm como parâmetros básicos de avaliação a porcentagem de germinação e de vigor como indicativos da fase ideal de maturidade das sementes. Em frutíferas como pitanga (Eugenia uniflora), o valor de germinação considerado indicativo da maturação das sementes é de $81 \%$. A maturação fisiológica foi verificada quando a altura, diâmetro e peso de frutos e sementes atingiram seus valores máximos, e o teor de umidade e massa seca das sementes tenderam a estabilização (Ávila et al., 2009). Para a arbórea Erythrina crista-galli, os valores do porcentual de germinação indicativos de maturidade das sementes são de 50\% (Lazarotto et al., 2011). Em quaresmeira (Tibouchina granulosa), Lopes et al. (2005) observaram que, no período na qual as sementes atingem sua maturidade fisiológica (77 e 110 DAA), a germinação média é de $12,5 \%$. Em cedro (Cedrela fissilis), o teor de umidade é um bom indicativo da maturidade fisiológica das sementes, e este é considerado ideal baseado na maior taxa de germinação (91,8\%) (Corvello et al., 1999). 
Como os resultados são variáveis para diferentes espécies, nem sempre é observada uma relação temporal (DAA) entre a germinação, vigor e acúmulo de matéria seca, como indicativo da maturidade fisiológica de sementes. Em calêndula (Calendula officinalis), por exemplo, não foi verificada tal relação temporal entre DAA e vigor (Silveira et al., 2002), sendo que a maturidade fisiológica foi relacionada a características físicas da semente. Em pimentão, a maturidade fisiológica das sementes também pôde ser relacionada a características físicas dos frutos (coloração) e da semente (teor de água) (Oliveira et al., 1999).

Em pimenta (C. annuum) verifica-se a relação temporal da maturidade fisiológica das sementes com a germinação e o vigor, além de maior atividade enzimática. Sementes coletadas 60 DAA apresentavam-se no seu maior estádio de maturação, sendo que estas não necessitaram de armazenamento pós-colheita para expressar o máximo poder germinativo (Oliveira et al., 1999; Vidigal et al., 2009).

Segundo Lee (1990), apesar da variável relacionada à maturação dos frutos e sementes mais conhecida e trabalhada ser o tempo para a origem dos mesmos, ou dias após a antese (DAA), a sua localização na planta também é um forte indicativo da maturação fisiológica. Santos et al. (2007), investigando a qualidade fisiológica de sementes de Mimosa caesalpiniaefolia, relacionaram a maturação com a posição do fruto no ramo, e ramos em diferentes vertentes (pontos cardeais), observando variação na qualidade fisiológica das sementes.

Dias et al. (2006) estudaram a maturação de sementes de tomate em função da posição dos frutos em diferentes racimos, na posição distal (apical) e proximal (basal). Estes observaram que, as sementes de frutos localizados na porção proximal (basal) dos racimos atingiram a maturação fisiológica precocemente com relação às sementes de frutos localizados na porção distal (apical). As sementes da porção basal apresentaram maior acúmulo de matéria seca e redução do teor de água. Observaram ainda que, sementes do racimo basal expressaram seu máximo poder germinativo mesmo sem que o conteúdo máximo de massa seca fosse atingido. Estes resultados corroboram com as afirmações da presente pesquisa, sendo que as sementes provenientes de frutos da porção basal da pimenteira apresentaram melhor qualidade física e fisiológica.

Desta forma, de acordo com o presente estudo, a posição dos frutos na copa e nos ramos pode ser um indicativo da maturidade fisiológica das sementes de pimenta malagueta. Sementes de frutos da porção basal da copa e dos ramos, representadas pelos tratamentos C3R2 e C3R3, apresentam melhor qualidade física (maior tamanho e peso), associada à melhor qualidade fisiológica (maior porcentual de germinação, maior índice de velocidade de germinação e menor tempo médio de germinação), além de melhor desenvolvimento inicial de plântulas (maiores valores de massa fresca e massa seca).

\section{Conclusões}

As sementes de frutos coletados na porção basal e mediana da copa, e basal dos ramos (C2R3 e C3R3) apresentaram maior PMS, associado ao maior comprimento e largura, além de maior valor para a porcentagem de germinação, maior índice de velocidade de germinação e menor tempo médio de germinação.

As sementes provenientes de frutos coletados na região basal (C3R3) propiciaram também o melhor desenvolvimento inicial de plântulas com relação ao comprimento da raiz, massa fresca e seca de plântulas.

\section{Referências}

ÁVILA, A.L.; ARGENTA, M.S.; MUNIZ, M.F.B.; POLETO, I.; BLUME, E. Maturação fisiológica e coleta de sementes de Eugenia uniflora L. (Pitanga), Santa Maria, RS. Ciência Florestal, v.19, n.1, p.61-68, 2009. http://cascavel.ufsm.br/revistas/ojs-2.2.2/index.php/ cienciaflorestal/article/view/420/293

BHERING, M.C.; DIAS, D.C.F.S.; VIDIGAL, D.S.; NAVIEIRA, D.S.P. Teste de envelhecimento acelerado em sementes de pimenta. Revista Brasileira de Sementes, v.28, n.3, p.64-71, 2006. http://www.scielo.br/ $\mathrm{pdf} / \mathrm{rbs} / \mathrm{v} 28 \mathrm{n} 3 / 10 . \mathrm{pdf}$

BRASIL. Ministério da Agricultura, Pecuária eAbastecimento. Regras para análise de sementes. Ministério da Agricultura, Pecuária e Abastecimento. Secretaria de Defesa Agropecuária. Brasília: MAPA/ACS, 2009. 395p. http://www.agricultura.gov.br/arq_editor/file/laborat\%c3\%b3rio/ sementes/regras\%20para\%20analise $\% 20 \mathrm{de} \% 20$ sementes.pdf

CONFORTI, F.; STATTI, G.A.; MENICHINI, F. Chemical and biological variability of peper fruits (Capsicum annum var. acuminatum L.) in relation to maturity stage. Food Chemistry, v.102, p.1096-1104, 2007. http://www.sciencedirect.com/science/article/pii/s0308814606005371

CORVELLO, W.B.V.; VILLELA, F.A.; NEDEL, J.L.; PESKE, S.T. Maturação fisiológica de sementes de cedro (Cedrela fissilis Vell.). Revista Brasileira de Sementes, v.21, n.2, p.23-27, 1999. http://www. abrates.org.br/revista/artigos/1999/v21n2/artigo04.pdf

DIAS, D.C.F.S.; RIBEIRO, F.P.; DIAS, L.A.; SILVA, D.J.H.; VIDIGAL, D.S. Maturação de sementes de tomate em função da ordem de frutificação na planta. Ceres, v.53, n.308, p.446-456, 2006. http://www. ceres.ufv.br/ceres/revistas/v53n308p06306.pdf 
FILGUEIRA, F.A.R. Solanáceas: agrometeorologia moderna na produção de tomate, batata, pimentão, pimenta, berinjela e jiló. Lavras, MG: UFLA, 2003. 333p.

LAZAROTTO, M.; BELTRAME, R.; MUNIZ, M.F.; BLUME, E. Maturação fisiológica de sementes de Erythrina crista-galli L. Ciência Florestal, v.21, n.1, p.9-16, 2011. http://cascavel.ufsm.br/revistas/ojs2.2.2/index.php/cienciaflorestal/article/view/2742/1668

LEE, T.D. Patterns of fruit and seed production. In: LOVETT DOUST, J.; LOVETT DOUST, L. (Ed). Plant reproductive ecology - patterns and strategies. Oxford: Oxford Univ. Press, 1990. p.179-209.

LOPES, J.C.; DIAS, P.C.; PEREIRA, M.D. Maturação fisiológica de sementes de quaresmeira. Pesquisa Agropecuária Brasileira, v.40, n.8, p.811-816, 2005. http://www.scielo.br/pdf/\%0d/pab/v40n8/a12v40n8.pdf

MAGUIRE, J.D. Speeds of germination-aid selection and evaluation for seedling emergence and vigor. Crop Science, v.2, p.176-177, 1962. https://www.soils.org/publications/cs/pdfs/2/2/cs0020020176

MARCOS-FILHO, J. Teste de envelhecimento acelerado. In: KRZYZANOWSKI, F.C.; VIEIRA, R.D.; FRANÇA-NETO, J.B. (Ed.) Vigor de sementes: conceitos e testes. Londrina: ABRATES, 1999. p.3.1-3.24.

OLIVEIRA, A.P.; GONÇALVES, C.P.; BRUNO, R.L.A.; ALVES, E.U. Maturação fisiológica de sementes de pimentão em função da idade dos frutos após a antese. Revista Brasileira de Sementes, v.21, n.2, p.88-94, 1999.

PEREIRA, T.S.; MANTOVANI, W. Maturação e dispersão de Miconia cinnamomifolia (dc.) Naud. na Reserva Biológica de Poço das Antas, Município de Silva Jardim, RJ, Brasil. Acta Botanica Brasílica, v.15, n.3, p.335-348, 2001. http://www.scielo.br/pdf/abb/v15n3/7579.pdf

PIÑA-RODRIGUES, F.C.M.; AGUIAR, I.B. Maturação e dispersão de sementes. In: AGUIAR, I.B., PIÑA-RODRIGUES, F.C.M., FIGLIOLIA, M.B. Sementes Florestais Tropicais. Brasília: ABRATES, 1993. p.215-274.
REIFSCHNEIDER, F.J.B. Capsicum: pimentas e pimentões no Brasil. Brasília, DF: EMBRAPA, 2000. 113p.

RUEDA-POENTE, E.O.; MURILLO-AMADOR, B.; CASTELLANOSCERVANTES, T.; GARCÍA-HERNANDEZ, J.L.; TARAZÓNHERRERA, M.A.; MEDINA, S.M.; BARRERA, L.E.G. Effects of plant growth promoting bacteria and mycorrhizal in Capsicum annuum L. var. aviculare ([Dierbach] D'Arcy and Eshbaugh) germination under stressing abiotic conditions. Plant Physiology and Biochemistry, v.48, p.724-730, 2010. http://www.sciencedirect.com/science/article/pii/ s098194281000080x

SILVEIRA, M.A.M.; VILLELA, F.A.; TILLMANN, M.A.A. Maturação fisiológica de sementes de calêndula (Calendula officinalis L.). Revista Brasileira de Sementes, v.24, n.2, p.31-37, 2002. http://www.scielo.br/ $\mathrm{pdf} / \mathrm{rbs} / \mathrm{v} 24 \mathrm{n} 2 / \mathrm{v} 24 \mathrm{n} 2 \mathrm{a} 06 . \mathrm{pdf}$

SANTOS, E.D.; ARAÚJO, R.R.; NETO, J.C.A. Avaliação da qualidade fisiológica de sementes de sabiá (Mimosa caesalpiniaefolia Benth.) em diferentes pontos de maturação. Agropecuária Científica no Semi-Árido, v.3, p.14-17, 2007. http://150.165.111.246/ojs-patos/index.php/acsa/ article/view/26/pdf

TORRES, S.B. Envelhecimento acelerado em sementes de pimentamalagueta (Capsicum frutescens L.). Ciência Agronômica, v.36, n.1, p.98-104, 2005. http://www.ccarevista.ufc.br/seer/index.php/ccarevista/ article/view/13/14

VIDIGAL, D.S.; LIMA, J.S.; BHERING, M.C.; DIAS, D.C.F.S. Teste de condutividade elétrica para semente de pimenta. Revista Brasileira de Sementes, v.30, n.1, p.168-174, 2008. http://www.scielo.br/pdf/rbs/ v30n1/a21v30n1.pdf

VIDIGAL, D.S.; DIAS, D.C.F.S.; VON PINHO, E.V.R.; DIAS, L.A.S. Alterações fisiológicas e enzimáticas durante a maturação de sementes de pimenta (Capsicum annuum L.). Revista Brasileira de Sementes, v.31, n.2, p.129-136, 2009. http://www.scielo.br/pdf/rbs/v31n2/v31n2a15.pdf 